\title{
An Interdisciplinary Robotics Course Using the Handy Board
}

\author{
Jerry Weinberg $^{1} \quad$ Cem Karacal $^{2} \quad$ George Engel $^{3} \quad$ Ai-Ping Hu $^{4} \quad$ William White $^{1}$ \\ Southern Illinois University Edwardsville \\ Edwardsville, IL, 62026, USA \\ Computer Science Department ${ }^{1}$ \\ Industrial \& Manufacturing Engineering Department ${ }^{2}$ \\ Electrical \& Computer Engineering Department ${ }^{3}$ \\ Mechanical Engineering Department ${ }^{4}$
}

\begin{abstract}
This study addresses the development of an handson undergraduate course that integrates various engineering fields involved in Robotic Systems.
\end{abstract}

\section{INTRODUCTION}

This National Science Foundation (NSF) funded study addresses the development of an undergraduate survey course in robotics that encompasses the various fields of engineering that are integral to robotic systems: Computer Science (CS), Electrical and Computer Engineering (ECE), Mechanical Engineering (ME), and Industrial \& Manufacturing Engineering (IME). The pedagogical goals of the course are:

- $\quad$ To provide a hands-on experience to practical robotics

- To learn about integrated system design

- $\quad$ To learn to interact with people in different disciplines in a cross-functional team

- To learn about group dynamics and teamwork

Another major goal of this project is to develop materials that provide an understanding of team development and group dynamics. The complexity of today's integrated systems requires cross-functional team development, so students need to learn to speak with people within other disciplines. As part of this goal, a team assessment method is developed that specifically addresses cross-functional aspects.

\section{BACKGROUND}

Hands-on robotics projects have become useful educational tools across a variety of subjects. Robots are complex integrated systems comprised of interdependent electrical, mechanical, and computational components. Because of their multidisciplinary nature, the study of robotics in the classroom has become a valuable tool for the practical, hands-on application of concepts in various engineering and science topics. They afford a view of information processing from the microprocessor level up through the application software, and are a perfect illustration of the connection between mechanical, electrical, and computing components. Further, robots are a physical embodiment of computational processes. The connection of the physical actions to the more abstract computation creates effective feedback for learning.

Platforms such as the Handy Board and the LEGO RCX have managed to allow educators enter into Robotics with little or no prior experience with the technologies involved. These robot platforms provide users with simple techniques for connecting sensors and motors, as well as straightforward methods for programming the controllers that manage those components in a variety of programming languages.

With the development of these inexpensive and accessible platforms, robotics projects provide an opportunity to directly interact with technology, as well as an opportunity to design and implement the various concepts that they embrace. The "constructionism" style of learning creates an active learning environment in which students can explore a significant design area, make hypotheses about how things work, and conduct experiments to validate their assumptions.

\section{A. Multidisciplinary Project Action Group}

To address the need for cross-disciplinary knowledge, we formed a Multidisciplinary Project Action Group (MPAG), which includes faculty members from Computer Science, Electrical \& Computer Engineering, Industrial \& Manufacturing Engineering, and Mechanical Engineering. The MPAG provides a basis for sharing expertise across the disciplines. The group's main goal is to share expertise for the purpose of using inexpensive robotics platforms for teaching engineering and computer science concepts. Consequently, students in mechanical engineering can learn enough about structured programming principles, behavior-based robotic control, and multitasking to successfully implement a control program. Conversely, computer science students can learn enough about sensor processing, gearing, and power transmission to successfully design a physical robot structure. The framework for sharing this expertise includes exercise design discussions, demonstrations, and guest lecturing. 
Members of the group create project modules that encompass concepts to be mastered in structured exercises for courses in their respective areas. These modules provide a basis of concepts and technical vocabulary for design discussions between the members. Through these discussions, the technical concepts of one discipline are translated into materials and exercises at a level that students in a complementary discipline can understand. The robotics projects have been included in every MPAG member's area of study (Table 1)

TABLE I

A SAMPLE OF CONCEPTS EMPHASIZED AND SHARED

\begin{tabular}{|l|l|l|l|}
\hline \multicolumn{1}{|c|}{ Area } & \multicolumn{1}{|c|}{ Course } & Concepts Emphasized & \multicolumn{1}{c|}{$\begin{array}{c}\text { Concepts } \\
\text { Shared }\end{array}$} \\
\hline $\begin{array}{l}\text { Computer } \\
\text { Science }\end{array}$ & $\begin{array}{l}\text { Artificial } \\
\text { Intelligence } \\
\text { (CS 438) }\end{array}$ & $\begin{array}{l}\text { Embedded agents, } \\
\text { deliberative/ reactive } \\
\text { robot control, planning, } \\
\text { multitasking }\end{array}$ & $\begin{array}{l}\text { Subsumption } \\
\text { architecture, } \\
\text { search } \\
\text { strategies, } \\
\text { multitasking }\end{array}$ \\
\hline $\begin{array}{l}\text { Mechanical } \\
\text { Engineering }\end{array}$ & $\begin{array}{l}\text { Robotics } \\
\text { Mechatronics } \\
\text { (ME 458) }\end{array}$ & $\begin{array}{l}\text { Sensor processing, logic } \\
\text { circuits, real-time } \\
\text { processing, actuators, } \\
\text { analog/digital } \\
\text { conversion, electro- } \\
\text { mechanical system } \\
\text { integration }\end{array}$ & $\begin{array}{l}\text { Differential } \\
\text { motion, } \\
\text { gearing, } \\
\text { translation } \\
\text { motion }\end{array}$ \\
\hline $\begin{array}{l}\text { Industrial } \\
\text { Engineering }\end{array}$ & $\begin{array}{l}\text { Engineering } \\
\text { Problem } \\
\text { Solving } \\
\text { (IE 106) }\end{array}$ & $\begin{array}{l}\text { Problem formulation, } \\
\text { structural design, } \\
\text { algorithmic design, } \\
\text { search strategies, } \\
\text { gearing, drive train }\end{array}$ & $\begin{array}{l}\text { Problem } \\
\text { analysis and } \\
\text { definition, } \\
\text { integrated } \\
\text { system design }\end{array}$ \\
\hline $\begin{array}{l}\text { Electrical \& } \\
\text { Computer } \\
\text { Engineering }\end{array}$ & $\begin{array}{l}\text { Senior } \\
\text { Project } \\
\text { (ECE 491) }\end{array}$ & $\begin{array}{l}\text { Signal processing, } \\
\text { robotic system design, } \\
\text { and project management, } \\
\text { analog/digital conversion }\end{array}$ & $\begin{array}{l}\text { Sensor } \\
\text { characteristics, } \\
\text { robotic system } \\
\text { integration, } \\
\text { robot } \\
\text { navigation } \\
\text { strategies }\end{array}$ \\
\hline
\end{tabular}

\section{B. Integrated Approach}

While the MPAG approach has been successful for introducing hands-on robotics projects in individual courses, it lacks three important educational goals that are addressed in this study. The first is the design and development of an integrated system. While the students in one area get a sense of how issues in the other disciplines might affect the design, they do not get a true experience of how to design a complex system of interdependent components from the different disciplines. The second educational goal is learning to work in cross-functional teams. A high degree of cooperation is needed among cross-functional team members for a project to be successful. The amount and type of communication, the amount and type of conflict, team cohesion and work processes appear to be the key areas in influencing cooperation and performance in cross-functional teams.

The final educational goal is a complete survey of the study of robotics. The MPAG approach has allowed us to introduce concepts from the different disciplines into each other's courses, but understandably each course still emphasizes concepts in its own specific area. So a course in ME emphasizes dynamics and kinematics while the course in CS emphasizes computational architecture. Students do not get exposure to the full breadth of robotics.

The laboratory components of the course mainly utilize the LEGO Building Block platform for the mechanical aspects of the robot and the Handy Board 6811-based microcontroller for the computational aspects. The accessories, tools, and material developed for the Handy Board are extensive and are useful in creating sophisticated assignments to challenge the students. For example, Drexel University's Research and Education Tools for Low-Cost Robots includes software tools for displaying the result of a certainty grid for navigation, tools for using the Handy Board's speaker for debugging, and tools for doing inter-robot infrared communication. A color camera developed at Carnegie Mellon University, called the CMUcam Kit, is available for the Handy Board. There is an extensive set of tested shareware labs that include sensor building, image processing, subsumption architecture, wave-front motion planning, and graph traversal.

\section{COURSE OUTLINE}

To meet these educational goals mentioned in the previous section, a new course, titled "Robotics: Integrated System Design”, has been developed for the Spring '04 semester. The course is cross-listed for credit for students in CS, ECE, ME, and IME with equal enrollment in each. We followed the schedule presented in Table I.

TABLE II

SSCHEDULE OF INTEGRATED ROBOTICS COURSE

\begin{tabular}{|c|l|}
\hline Week & \multicolumn{1}{c|}{ Lecture and Lab Topics } \\
\hline \hline 1,2 & $\begin{array}{l}\text { Introduction to Robotics, Introduction to Handy Board \& IC4 } \\
\text { Programming, Teamwork and group dynamics }\end{array}$ \\
\hline 3,4 & $\begin{array}{l}\text { Definitions, DoF, Spatial Descriptions, Servo } \\
\text { Motors, Sensors, Actuators, and encoders }\end{array}$ \\
\hline $4,5,6$ & Forward and Inverse Kinematics, Control Principles \\
\hline $7,8,9$ & $\begin{array}{l}\text { Operating Principles for Several Sensors, Advanced sensors, } \\
\text { Custom Sensor Design }\end{array}$ \\
\hline 10 & Computer Vision \& Vision Programming \\
\hline 12,14 & $\begin{array}{l}\text { Mobile Platforms, Motion Planning: Road Maps, Graph Search, } \\
\text { Cell Decomposition. Embedded Systems Programming, } \\
\text { Configuration Space Matrix Transformations, } \\
\text { systems, Centralized, Distributed, Market-based approaches }\end{array}$ \\
\hline 15 & USAR Preparation and Competition \\
\hline 16 & Final Review \\
\hline
\end{tabular}

In addition to the covering material traditionally presented in separate courses in different disciplines, we created a cohesive course structure that exposes students to all aspects of robotics. The homework and lab assignments are reflective of our integrated approach.

\section{B. Homework Assignments}

The first assignment is on Kinematics and given immediately after forward and inverse kinematics lectures. The assignment covers areas such as finding the position and orientation of two/three link revolute/prismatic joint robot 
arms. Through this assignment, students other than ME are exposed to the basics of kinematics.

The following assignment is on sensor electronics. This assignment is given after an introductory lecture on electronics basics for sensors and involves problems on designing a simple first-order, passive RC, lowpass filter, non-inverting gain amplifier using a TLC2272 op-amp, determining Vout/Vin for a given op-amp circuit, etc.

\section{Lab Assignments}

The very first lab assignment given is a Rube Goldberg Machine that will capture a mouse without harming it (see Figure 1). The machine must consist of at least 5 energy transfers (steps). The students are allowed to use the nonelectronic parts from your robotics kits. However, they may add other materials, except batteries or power supplies. This assignment gives students the opportunity to get themselves familiar with the mechanical Lego components provided in their robotics kits.

The second assignment is designed to help students learn about the electronics components of their kits as well as giving them the chance to practice with IC4. The assignment involves simulating a bug behavior (see Figure2). The objective is to build a mobile bug that should wakeup when a strong light is shined on it. Then, the bug should scan the area in front of it for the closest object, which it will assume, is a food source. The bug should use the sonar sensor placed on a turret mechanism for this. The turret must be turned by a servo motor. Once the bug identifies the closest object, it should move in the direction of the object. Depending on how the bug determines the direction of the object, this may require rescanning. When the bug finds the food with its antennae, it stops to feed using touch sensors as the antennae. If the food source is removed, the bug searches for a new food source.

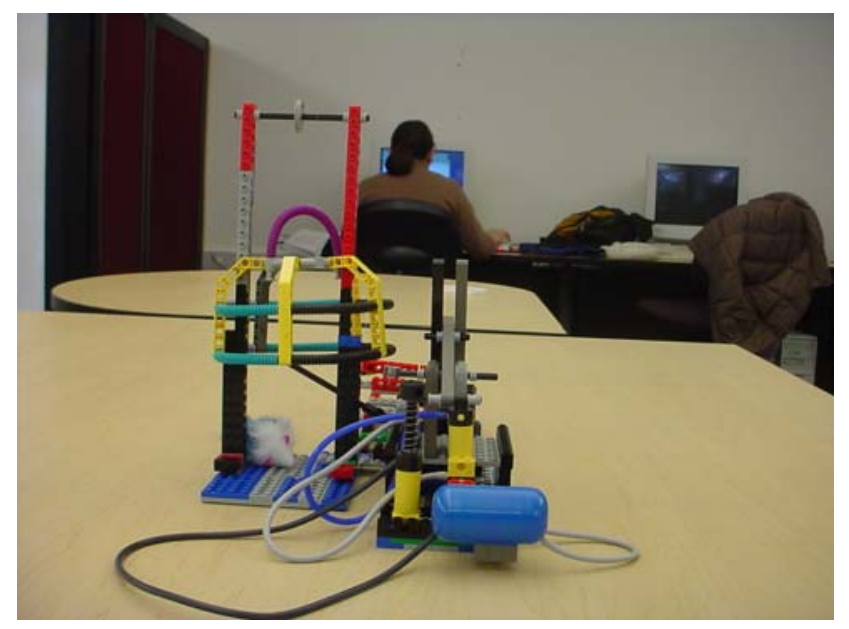

Figure 1. A Lego Rube Goldberg Machine using vacuum pump.

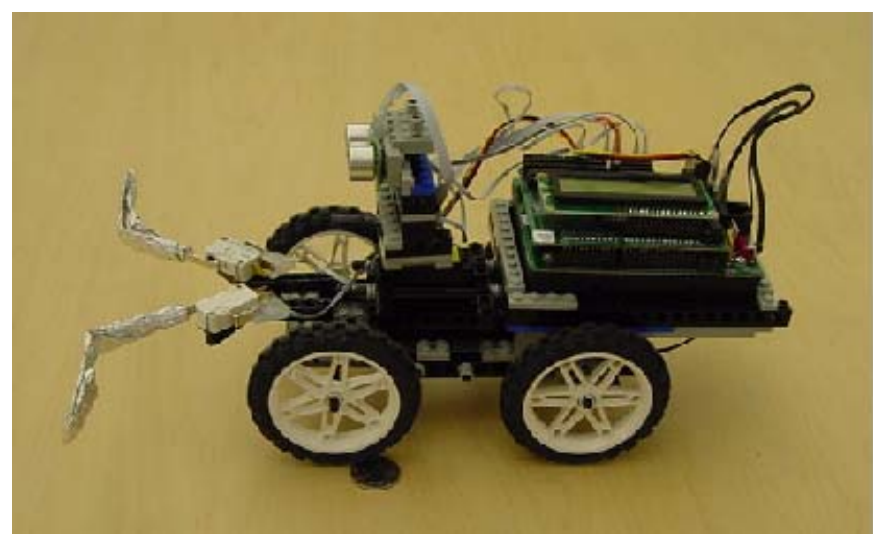

Figure 2. A Lego-bug with sonar sensor.

The third assignment is about Sensor Electronics and requires designing and fabricating a Custom Light Sensor for use with the Handy Board that can "home in" on a light source (see Figure 3). The goal area is defined as the set of all points in the working plane within 6" of the light source. The robot's initial position and orientation with respect to the source will be unknown, but but is about 24" away, and the initial heading will diverge no greater than approximately 45 degrees from the optimal path to the source. The light source will consist of small light bulb located in the center of the circle and elevated off the surface by a distance of approximately 6 inches. Initially, the light source will be turned off. The light will remain off for a minimum of 15 seconds. The robot should remain "quiet" until the light source is turned on. Once the light source is turned on, the robot should "home-in" on the source as quickly as possible.

The fourth assignment is on designing a two-link manipulator robotic arm that accurately track a 1" circular closed path with its tip (see Figure 4). The center of the circle is located at World Coordinates ( $\mathrm{X}=0$ " and $\mathrm{Y}=6$ "). The tip motion is required to trace out the circle in a counterclockwise direction as fast as possible both starting and ending at coordinates ( $\mathrm{X}=1$ " and $\mathrm{Y}=6$ "). The link lengths of the manipulator are 6" and 25". This leads to two inverse kinematics solutions to the given task. A proportional Derivative Proportional (DP) closed-loop control needs to be implemented by the students to achieve the desired accuracy. Two $25 \Omega$ rotational potentiometers are required to be used to sense the joint angles.

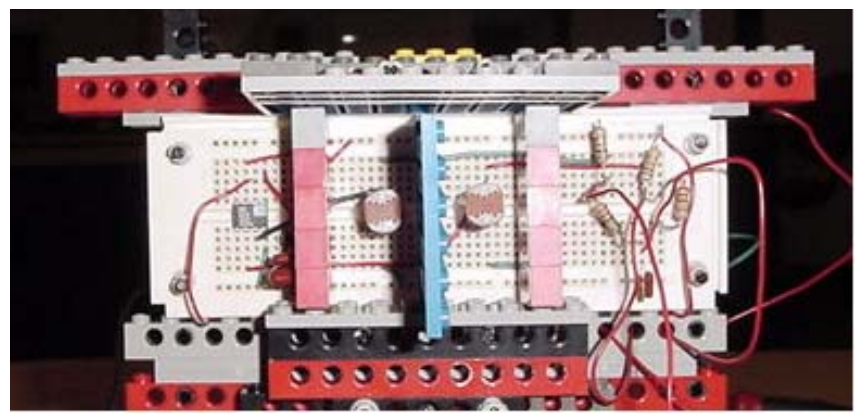

Figure 3. A student designed \& implemented custom light sensor. 


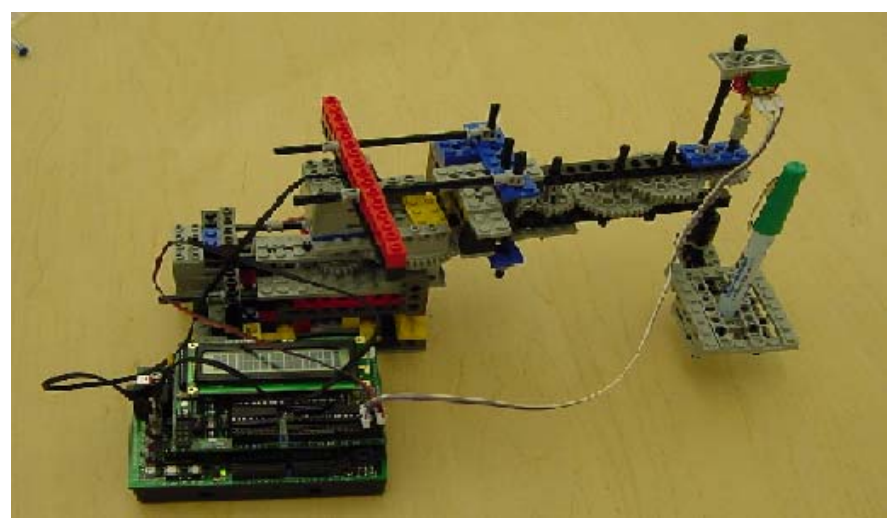

Figure 4. A two-link robotic arm.

The final lab project is on Urban Search \& Rescue project. The objective of the project is to design and implement an autonomous search and rescue robot for an earthquake damaged building. The robot should design and implement a custom sensor for sound localization in addition to designing and implementing an algorithm for autonomous navigation. The search area is a 10x10' area with various obstacles and divided into 5 rooms and a sixth room located in the upper level. The robot is to locate all victims wearing specific color uniform as well as a victim screaming for help. Once discovered, the robot should approach the victim (less than 1 '), set off a series of beeps, and record the exact location of the victim.

The details of all homework and lab assignments along with video clips of student project demonstrations can be viewed at www.cs.siue.edu/robotics/integratedsystems.

\section{EVALUATION}

The evaluation will focus on the three main educational goals of the project: 1) provide a robotics survey course for students in the different disciplines, 2) create a crossfunctional team experience, and 3) develop course material that can be taught by an individual faculty member in one discipline. The cross-disciplinary robotics course affords a unique opportunity to gauge how well team members need to grasp each other's areas on such projects, as well as how successful the course is in achieving that understanding. The assessment mechanisms to be used include:

- After presenting the basic robotics concepts of a certain discipline, the students would be tested on those concepts. Presumably, individuals from the discipline in question will have less difficulty with these questions, and their scores may be used as a gauge for how well the students from the other disciplines grasped the material.

- After the initial robotic project design, teams will be given in-class presentations in which their design decisions will be explained. By having each student explain the rationale for design decisions that involve the disciplines of the other team members (e.g., the ME student explains the algorithmic design of the robot's control program, and the CS student explains the structural design of the physical platform) an assessment can be made of how well each team member grasps the additional engineering and scientific principles being applied.

- Each project will conclude with a written summary that stresses the interaction between the disciplinary concepts that were applied to the project's development. Written by the entire team, the summary may be used to determine the extent to which the team integrated each discipline into the project, as well as the degree to which that integration was understood by the team.

\section{ASSESSMENT}

Previous efforts to implement multidisciplinary curricular components have been widespread, and efforts to assess their success have varied widely. Rover and Fisher [35] relied on journals for individual self-assessment and project presentations for team assessment. King, et al. [36], utilized student evaluation forms as well as evaluations by independent faculty teams. Aldridge and Lewis [37] had students provide feedback to their project teammates. Fruchter and Emery [38] designed a metric by which cross-disciplinary comprehension could be progressively gauged. While this project will build on these efforts, we also intend to experiment with several innovative techniques for evaluating multidisciplinary teamwork and communication. Prominent among these will be the development of exams to determine how extensively students from one discipline must comprehend the fundamental concepts of another discipline, and how successful they are at accomplishing that feat.

The first offering of the course is being taught as a team effort. Individual instructors provide material in their discipline. This will provide the MPAG members an opportunity to hone the material before completing the extensive supplementary instructor material. One or two individuals will teach the second offering of the course. A comparison of the above assessment between the two offerings will provide an evaluation of how well the MPAG was able to craft the course material so that it could be taught in departments that do not have the same faculty resources or MPAG framework. During this second offering careful monitoring will take place to insure that instructors and students do not obtain extensive assistance from the other MPAG faculty that would negate the comparison of the two semesters.

\section{ACKNOWLEDGEMENTS}

This project was funded in part by the National Science Foundation, Division of Undergraduate Education, Grant Award \# DUE-0311434. We would also like to thank Howie Choset for his guidance and allowing us to adopt materials 
from his General Robotics Course at CMU

(www.generalrobotics.org).

\section{REFERENCES}

[1] Beer, R., Hillel, C., and Drushel, R., "Using Autonomous Robotics to Teach Science and Engineering," Communications of the ACM, Vol. 42, No. 6, June 1999, pp. 85-92.

[2] Norstrand, B., "Autonomous Robotics Projects for Learning Software Engineering," Proceedings of the 2000 IEEE International Conference on Systems, Man \& Cybernetics, Nashville, August 2000, pp. 724-729.

[3] Avanzato, R., "Mobile Robotics for Freshman Design, Research, and High School Outreach," Proceedings of the 2000 IEEE International Conference on Systems, Man \& Cybernetics, Nashville, August 2000, pp. 736-739.

[4] Meeden, L., "Using Robots as Introduction to Computer Science," Proceedings of the Ninth Florida Artificial Intelligence Research Symposium, Key West, 1996, pp. 473-477.

[5] Kumar, D. and Meeden, L., "A Robot Laboratory for Teaching Artificial Intelligence," Proceedings of the Twenty-Ninth SIGCSE Technical Symposium on Computer Science Education, Atlanta, 1998, pp. 341-344.

[6] Gaines, D., and Balac, N., "Using Mobile Robots to Teach Artificial Intelligence Research Skills," Proceedings of the 2000 ASEE Annual Conference, St. Louis, June 2000.

[7] Fagin, B, “Ada/Mindstorms 3.0: A Computational Environment for Introductory Robotics and Programming”, IEEE Robotics and Automation, 2003.

[8] Klassner, F, “A Case Study of LEGO Mindstorms Suitability for Artificial Intelligence and Robotics Courses at the College Level”, Proceeding of the $33^{\text {rd }}$ SIGCSE Technical Symposium on Computer Science Education, Northern Kentucky, February 2002, pp. 8-12.

[9] Jadud, M., "TeamStorms as a Theory of Instruction," Proceedings of the 2000 IEEE International Conference on Systems, Man \& Cybernetics, Nashville, August 2000, pp. 712-717.

[10] Papert, S. Mindstorms: Children, Computers, and Powerful Ideas, Basic Books Inc., 1980.

[11] Fagin, B. "Using Ada-Based Robotics to Teach Computer Science", Proceedings of the 5ht ITICSE Conference, Helsinki, Finland, July 2000.

[12] Schreiner, K. "Retail Robots on the Move”, IEEE Intelligent Systems, Vol. 16, No. 2, March/April, pp. 4-6.

[13] Martin, F., Mikhak, B., Resnick, M., Silverman, B., and Berg, R., “To Mindstorms and Beyond: Evolution of a Construction Kit for Magical Machines," Robots for Kids: Exploring New Technologies for Learning; A. Druin and J. Hendler, eds., Morgan Kaufmann, 2000, pp. 9-33.

[14] Saffo, P., "The Consumer Spectrum," in Bringing Design to Software, T. Winograd, ed., Addison-Wesley, 1996.

[15] Knudsen, J., The Unofficial Guide to LEGO Mindstorms Robots, O’Reilly \& Associates, 1999.

[16] Bagnall, B., Core LEGO MINDSTORMS Programming: Unleash the Power of the Java Platform, Prentice Hall, 2002.

[17] Turkle, S. and Papert, S., "Epistemological Pluralism and the Revaluation of the Concrete," Journal of Mathematical Behavior, Vol. 11, No. 1, March 1992, pp. 3-33.

[18] Miller, G., Church, R., and Trexler, M., "Teaching Diverse Learners Using Robotics," Robots for Kids: Exploring New Technologies for Learning, A. Druin and J. Hendler, eds., Morgan Kaufmann, 2000, pp. 165-192.

[19] Weinberg, J.B., G.L. Engel, K. Gu, C.S. Karacal, S.R. Smith, W. W. White, and X. Yu. "A Multidisciplinary Model for Using Robotics in Engineering Education.” ASEE 2001 Conference, June 2001; Published on CD

[20] Weinberg, J.B. and G. Mayer. “A Multidisciplinary Project Action Group”, Working Papers of the Spring 2001 American Association of Artificial Intelligence Spring Symposium; Session on Robotics \& Education, March 2001.
[21] Pinto, M.B., and J. K. Pinto, "Project Team Communication and CrossFunctional Cooperation in New Program Development," Journal of Product Innovation Management, 1990, volume 7, pp. 200-212.

[22] Ruekert, R.W., and O.C. Walker, "Marketing's Interaction with Other Functional Units: A Conceptual Framework and Empirical Evidence," Journal of Marketing, 1987, volume 51, pp. 1-19.

[23] Song, X.M., M. M. Montoya-Weiss, and J.B. Schmidt, "Antecedents and Consequences of Cross-Functional Cooperation: A Comparison of R\&D, Manufacturing, and Marketing Perspectives," Journal of Product Innovation Management, 1997, Volume 14, pp. 35-47.

[24] Rosenblatt, M. and H. Choset, "Designing and Implementing Hands-on Robotics Labs”, IEEE Intelligent Systems, November/December 2000, pp. 32-39.

[25] Brockman, J. "Multidisciplinary Engineering Design Laboratory Course Philosophy”, Web Site: www.nd.edu/ lego/philosophy.html, May 2001.

[26] Hartfield, B. “The Designer's Stance,” in Bringing Design to Software, T. Winograd, ed., Addison-Wesley, 1996.

[27] Engineering Accreditation Commission (Accreditation Board for Engineering and Technology, Inc.); 2001-2002 Criteria for Accrediting Engineering Programs; December 2000; Web site: www.abet.org/images/eac_criteria_b.pdf/.

[28] Choset, H., "25-354 General Robotics", Course Web site: www.generalrobotics.org

[29] The Robotics Institute at CMU, Web site: www.ri.cmu.edu

[30] Greenwald, L, and J. Kopena, "On Achieving Educational and Research Goals with Small, Low-Cost Robot Platforms”, IEEE Robotics and Automation, To Appear Spring 2003.

[31] Greenwald, L., “Tools for Effective Low-Cost Robotics”, Working Papers of the Spring 2001 American Association of Artificial Intelligence Spring Symposium; Session on Robotics \& Education, March 2001.

[32] Weinberg, J. B. \& M. Stephen, “A Laboratory Experience for Teaching Participatory Design in a Human-Computer Interaction Course”, 2002 American Society for Engineering Education, June 2002, published on CD.

[33] Rowe A., C. Rosenberg, I. Nourbakhsh, "A Low Cost Embedded Color Vision System." Proceedings of the 2002 IEEE/RSJ International Conference on Intelligent Robots and Systems, October 2002.

[34] Martin, F. Robotic Exploration: A hands-on introduction to engineering, Prentice-Hall, Inc., 2001.

[35] Rover, D. T. and P. D. Fisher; "Cross-Functional Teaming in a Capstone Engineering Design Course"; Proceedings of the Frontiers in Education 1997 Conference; November 1997; pp. 215-219; Web site: http://fie.engrng.pitt.edu/fie97/papers/1018.pdf/.

[36] King R., T. E. Parker, T. P. Grover, J. P. Gosink, and N. T. Middleton; "A Multidisciplinary Engineering Laboratory Course"; Journal of Engineering Education; Vol. 88, No. 3; July 1999; pp. 311-316; Web site: http://www.asee.org/jee/papers/KING-311.pdf /.

[37] Aldridge, D. and P.M. Lewis; "Multi-Disciplinary Teams: How to Assess and Satisfy ABET Criteria”; Symposium on Best Assessment Processes in Engineering Education; Rose-Hulman Institute of Technology; April 1997; Web site: www.egr.msu.edu/classes/cps479/reading/TeamDesign.html/.

[38] Fruchter, R. and K. Emery; “Teamwork: Assessing Cross-Disciplinary Learning”; Proceedings of the Computer Support for Collaborative Learning 1999 Conference; December 1999; pp. 166-173; Web site: http://kn.cilt.org/cscl99/A19/A19.HTM/. 